\title{
Large freshwater and sediment impoundments between the Mississippi River and the Louisiana coastline
}

\author{
GLEN R. ANDERSEN 1 , BRAD HALL ${ }^{2}$ \& E. MARCO AIETA ${ }^{3}$ \\ 1 AMEC Environmental \& Infrastructure, 2000 East Edgewood Drive, Suite 215, Lakeland, Florida 33803, USA \\ glen.andersen@amec.com \\ 2 Northwest Hydraulic Consultants, 3950 Industrial Blvd, Suite 100C, West Sacramento, California 95691, USA \\ 3 AMEC Environmental \& Infrastructure, 2000 South Colorado Blvd, $10^{\text {th }}$ Floor, Denver, Colorado 80222, USA
}

\begin{abstract}
An innovative system-level sediment and freshwater management plan is proposed for the coastal regions of Louisiana, USA. It involves the construction of large sediment and freshwater impoundments between the river and coastline fed periodically through large spillway structures during the rising hydrograph of the river when the highest concentration of sediment is in the water column. Sediment directing and trapping technologies are proposed for the river channel and spillways to capture the coarsergrained sediments. The embankments can be constructed from dredging and then enlarged by land-based harvesting of coarse-grained sediments from the traps. These impoundments will permit the continuous introduction of freshwater and finer-grained sediments to coastal marshlands for vegetation, land augmentation, protection from storm surges and salt water intrusion, while removing large amounts of sand from the river and decreasing annual maintenance dredging costs.
\end{abstract}

Key words system-level sediment and freshwater management plan; large impoundments; system-level diversions; sediment traps; land augmentation

\section{INTRODUCTION}

The Mississippi River is the single most important natural feature in the continental United States, draining $41 \%$ of the land mass through its tributaries. It has been a backbone of commerce and industry since before the founding of our country and everyone that has lived in the United States has been its beneficiary in one way or another. Recognizing the power and vital strategic importance of the Mississippi, our Nation sought to optimize its usefulness by channelizing and attempting to make its behaviour more predictable. Flood control structures, navigational structures, and power generation facilities have all been added over the years.

The Mississippi River and the southern Louisiana coastline is a highly integrated and very complex system that directly affects the lives of the local inhabitants and the viability of a significant number of critical industries. We have only recently begun to realize the long-term consequences that manmade projects have had on the River's vulnerable communities and industries, many of which are experiencing critical loss of coastal lands, fisheries, severe flooding hazards, and rising maintenance-of-navigation costs. However, without a change to the manner in which we manage the River's water and sediment flows, Southern Louisiana will continue to experience: (1) severe loss of coastline; (2) increasing severity of coastal flooding; and (3) unsustainable maintenance dredging costs.

While some have suggested that these three severe issues be addressed by changing the course of the River, the purpose of this paper is to propose a system-level management plan that is a less radical and more predictable. The approach proposed herein is focused on restoring the delta creation function to rebuild the coastline while at the same time strengthening existing flood protection systems, and both of these being performed in a manner that decreases annual maintenance of navigation costs by removing sediments from the River. 


\section{DELTAIC FUNCTION}

The present Louisiana coastline is a product of approximately 5000 years of delta building by the Mississippi River after the final sea level rise corresponding to the end of the last ice age. Over this 5000 year period the River has followed seven different courses, creating a separate delta for each. Kolb and Van Lopik (1958) provide a useful summary of this delta building process along with a figure and table. Proceeding from oldest to youngest, these deltas are known as: (1) SaleCypremort; (2) Cocodrie; (3) Teche; (4) St Bernard, Metairie, Barataria - La Loutre; (5) Laforche; (6) Plaquemines; and (7) Balize.

As each of these deltas was being formed, the sediments deposited by the River began a process of primary consolidation wherein the excess pore water is squeezed out from between the soil particles as a result of the increasing sediment load being deposited on top of them. Through primary consolidation the sediments become more tightly compacted and stronger. Coarser grained sediments (gravels and sands) consolidate almost instantaneously because of their high permeabilities while finer-grained sediments (silts and clays) can take substantially longer to consolidate, depending upon the thickness of the deposit and the location of interspersed coarsergrained sediment layers. In fact, this process is still active and some of the sediments in Southern Louisiana are still undergoing primary consolidation.

After the sediments have completed primary consolidation (meaning that the initial excess pore water pressures have fully dissipated) the process of secondary consolidation continues. Secondary consolidation is where the soil particles slowly rearrange themselves, but in the absence of excess pore water pressures.

The surficial manifestation of primary and secondary soil consolidation is settlement. In order for a delta to maintain landmass, it is therefore necessary that the rate of sediment deposition be at least equal the rate of settlement. When the amount of sediment being deposited is greater than the amount of settlement the delta grows, when it is less the delta shrinks. When the River changed its course in the past, the sediment load was cut off from the existing delta and continuing primary and secondary consolidation caused a loss in ground surface elevation resulting in loss of coastline, saltwater intrusion and loss of marsh lands and other freshwater habitats. These effects are being experienced along most of the Louisiana coastline away from the current Balize Delta.

It is important to note that the type of sediments carried by the Mississippi River is highly dependent upon the amount of energy available. Coarser-grained sediments have higher strength and are more resistant to erosion, but they are typically deposited further up river. These coarse grained sediments are ideal for roadways, buildings and flood control structures. Unfortunately, the sediments that have formed the Mississippi deltas are weaker and less resistant to erosion. Thus, in order to maximize the delta creation energy of the Mississippi, any approach will need to bring coarser-grained sediments closer to the coastline than are presently being deposited by the River and existing distributary channels.

\section{MAN'S EFFECT ON THE RIVER}

Due to navigational enhancements in the early 1800s near present day Angola, LA, the River began shedding a larger percentage of its water and sediment flows down the Atchafalaya River. By the mid-1900s the percentage of flow going down the Atchafalaya was so large that the Corps of Engineers projected that the Mississippi River would entirely shift its course by 1990. Such a shift would have had catastrophic effects on industry and navigation and on the communities between Baton Rouge and the Head of Passes that had been built up to take advantage of the River. As a result, a decision was made to artificially control the amount of water that would flow out of the Mississippi River and into the Atchafalaya by building what is known as the Old River Complex. This set of structures was initially completed in the early to mid-1960s, and along with the subsequently completed Auxiliary Structure and Sidney A. Murray Hydropower facility has been able to maintain the water flows at about $70 \%$ in the Mississippi and about $30 \%$ in the Atchafalaya. 
Nordin and Scott (1992) measured the gradation of the Mississippi River bed sediments along the thalweg in a research project during 1989 and concluded that most of the bed gravels were being deposited upstream of New Orleans. In the New Orleans area the River's bed load was found to consist almost entirely of fine sand $(0.25-0.125 \mathrm{~mm})$ and very fine sand $(0.125-0.063$ $\mathrm{mm}$ ). They also concluded that the bed sediments measured in 1989 were finer (less medium and coarse sand and less gravel and had significantly more very fine sand) than measured in 1932.

Thorne et al. (2008) conducted research on the current and historical sediment loads in the lower Mississippi River. While being very cautious in their conclusions, because of various difficulties in comparing the historical record with measurements based upon modern technologies, they nevertheless concluded that there has been a long-term decline in the amount of sediments being transported by the River to the Louisiana coastline. During the 19th and early 20th centuries, the quantity and calibre of sediments being transported by the River increased due to land-use and river management practices. However, in the later part of the 20th century with soil conservation, improved land management practices, and engineering on the River and its tributaries the quantity and calibre of the sediments has decreased.

The implication of the Nordin and Scott (1992) study and the Thorne et al. (2008) study is that over the years, with our continued soil conservation and engineering along the river, there is a lower percentage of coarse-grained and higher strength sediments available for the delta building function. These efforts have a direct negative impact on the southern Louisiana coastline.

\section{PROPOSED SYSTEM-LEVEL RIVER MANAGEMENT PLAN}

In the authors' opinion, the original delta building function of the Mississippi River can be mimicked for the southern Louisiana coastline by installing a series of very large spillways (similar in size to the Bonnet Carre spillway) and by creating a series of very large freshwater and sediment impoundments that are fed periodically by the Mississippi River through these spillways. During the late winter and early spring when the flow rate in the lower Mississippi River typically increases to a maximum and the amount of energy increases towards its maximum annual value, the greatest amount of sediment (both coarse and fine-grained) becomes suspended in the water column and is available for delta building. The system basically mimics in a regulated fashion the historical processes of avulsion of flood flows and their associated sediment loads into the intervening freshwater marshlands between the River and the Louisiana coastline.

In summary, our proposed system-level river management plan is to:

\section{"Capture large portions of the freshwater and sediments during the late winter and early spring when flow rates are sufficient and sediment loads are at a maximum and store these in large surface impoundments constructed between the Mississippi River and the Gulf Coast."}

Based upon historical river stage data and existing ground surface topography between the River and the coastline, sufficient head is available in the general vicinity of New Orleans under average hydrograph conditions to periodically fill these impoundments and then slowly release freshwater into coastal areas throughout the year, enhancing marsh vitality during the growing season.

Figure 1 presents a schematic representation of how surface impoundments between the Mississippi River and the Gulf Coast might be sited. Each of these sediment impoundment areas can consist of a double-gated spillway and one or more large impoundments formed by constructed earthen embankments. Both sets of spillway gates can be opened to permit the freshwater and sediments to fill the impoundment areas. Both sets of gates can then be closed and a set of secondary gates can then be used to dewater the spillway area. The spillways can have approximately the same flow capacity as the Bonnet Carre spillway, but can also incorporate sediment traps to capture a significant fraction of the coarse-grained bed material sediments. The location of these large spillways can be sited at locations along the river channel to enhance the opportunity for capturing coarse-grained bed material sediments. In addition, sediment directing features can be installed in the River channel in order to maximize the amount of bed material sediments that enter the spillway during an opening. 
Freshwater release gates can be strategically located at external boundaries of the impoundments or can be located to permit the exchange of water between impoundments. Idealized locations for these gates are presented in Fig. 1 for illustration only. These freshwater gates can be a continuous source of freshwater to nearby swamp and marsh habitats to moderate the effects of salt intrusion during low flows in the River.

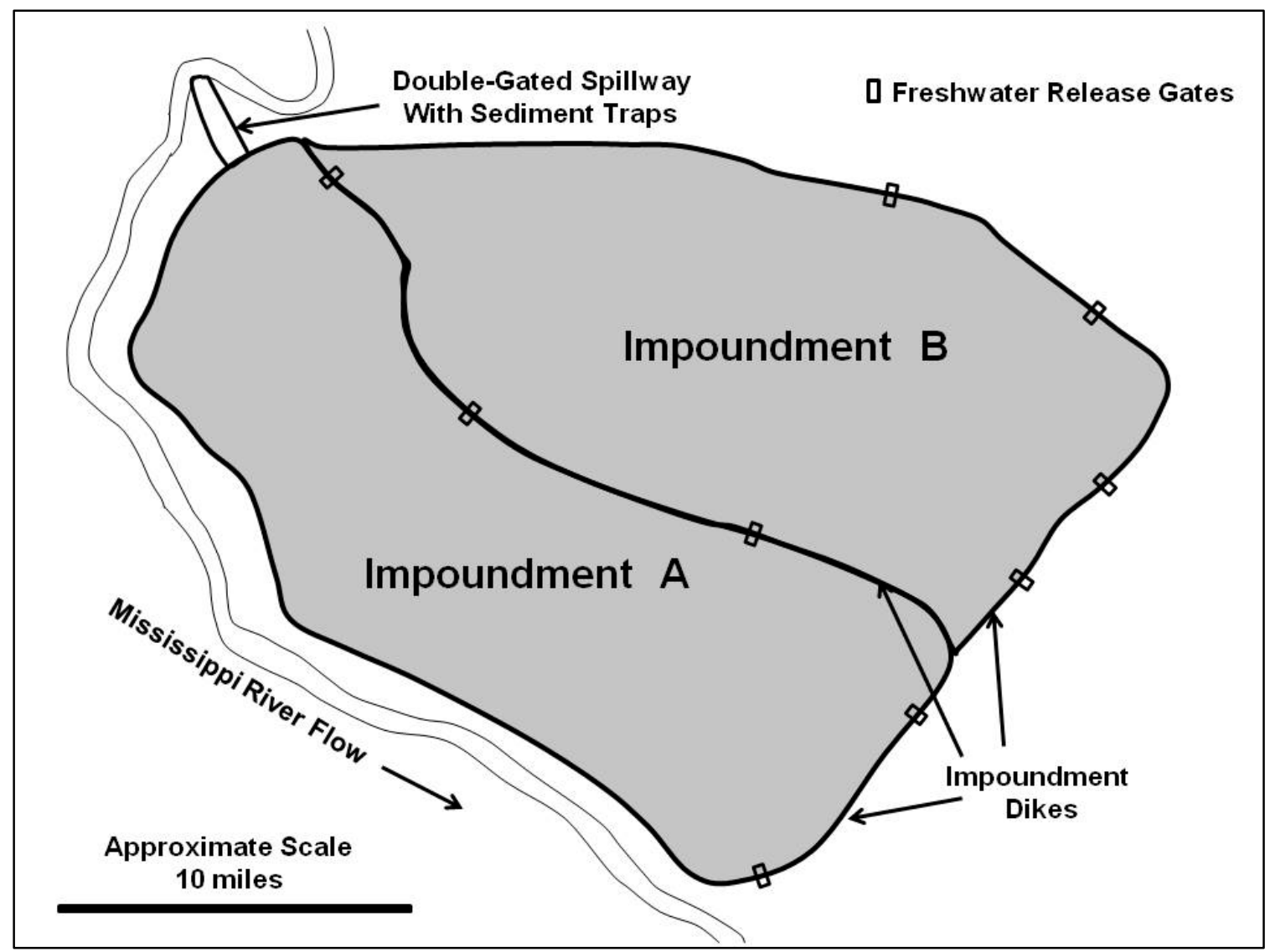

Fig. 1 Schematic diagram of potential impoundment areas.

Locations for these above-ground impoundments are similar to very large low-lying areas where current lakes exist or where they may have existed historically. These would be immediately adjacent to coastal marsh areas or they would drain into these areas. One such location might be the Big Mar - Lake Lery area just across the River from Belle Chase. Another location might be the Lake Cataouatche - Lake Salvador area south and west of New Orleans, and a third location might be the Lac des Allemands area south and west of LaPlace. More specific impoundment locations and dimensions would be determined in the initial screening evaluation of this restoration alternative.

The initial embankments for these impoundment areas can be formed by a combination of dredging and fill placement. As the sediment traps are mined for the coarse-grained sediments after the periodic filling operations, these can be used to strengthen, augment and extend the embankments. With properly designed spillways and sediment-directing technologies placed in the River, a series of such capture and impoundment systems could remove a substantial portion of the annual sand load from the River thus eventually decreasing the annual maintenance of navigation costs on the lower River.

These captured sediments are high quality land building materials and being deposited in the spillways, these will be readily available for other construction projects in low-lying areas. Landbased excavation and transportation equipment can be used and these materials will be closer to the actual areas where they are needed. Hence, these will create a low-cost source of fill materials 
that can be used for: improvements to existing flood protection systems; building new flood protection systems; land building; and bank stabilization.

Fine grained sediments that are initially suspended in the impoundments will slowly settle into the basins thus adding to the landmass, and supplementing the bioaccumulation of organic sediments that results from marsh growth. In addition, the seaward boundaries of these impoundments will also function as hurricane storm surge barriers decreasing the severity of inland flooding.

These basins could be segmented so that a land augmentation program could be implemented in conjunction with creating and enhancing freshwater swamps and marshes by switching between basins every two to three decades.

\section{EVALUATION OF BENEFITS}

The proposed system-level river management plan provides the following benefits to southern Louisiana.

(a) Freshwater impoundments near the coastline

(b) Continuous release of freshwater and sediments

(c) Removal of substantial portion of annual sediment load from the River

(d) Trapping of sandy sediments in spillways

(e) Gradual siltation of impoundments; and

(f) Seaward embankments function as seawalls

The Louisiana Coastal Protection and Restoration Authority (CPRA) identified nine decision criteria in the 2012 Coastal Master Plan that are to be used in evaluating the benefits of any proposed improvement. These are: (1) Support cultural heritage; (2) Distribute flood risk reductions across socio-economic groups; (3) Flood protection of historic properties; (4) Flood protection of strategic assets; (5) Support of oil and gas; (6) Support of navigation; (7) Use of natural resources; (8) Operations and maintenance costs; and (9) Sustainability. The following is a brief discussion of the benefits that a system of freshwater and sediment impoundments can have in terms of the nine CPRA decision criteria.

\section{Freshwater impoundments near coastline}

These large freshwater impoundments will support the Louisiana cultural heritage and enhance the use of natural resources by providing increased fishing and freshwater recreation opportunities and by combating the effects of saltwater intrusion so that the communities can become more resilient. The operations and maintenance costs for these freshwater impoundments are associated with the periodic filling operations and controlled releases. These impoundments are sustainable through the continuous production of low-cost high quality fill materials.

\section{Continuous release of freshwater and sediments}

The continuous release of freshwater and sediments will support the cultural heritage and the use of natural resources by increasing the size of coastal marshlands and strengthening freshwater fish and animal populations. By increasing the size of coastal marshlands, they will provide an additional land buffer for flood-prone communities and industries, thus evenly distributing flood risk reductions, protecting historical properties, protecting strategic assets and supporting oil and gas operations. The release of freshwater and sediments from these impoundments can be automated to reduce long-term costs. The Mississippi River provides a sustainable source of freshwater and sediments.

\section{Removal of annual sand load from the river}

The sediment directing technologies and the sediment traps can be designed to remove a substantial amount of the annual sand load in the River. This can have the long-term effect of decreasing annual maintenance dredging costs. In addition, the high-quality coarse-grained 
sediments represent a natural resource that can be transported at low cost across land or along the previously constructed embankments in order to get them much closer to the coastline and to create or enhance sediment barriers, restore natural banks and construct other structures, thus mimicking the natural land building process and helping the nearby communities to become more sustainable.

\section{Trapping of sandy sediments in spillways}

The availability of local and low-cost structural fill in flood prone areas will permit the construction and enhancement of primary flood protection facilities. This in turn will help to distribute flood risk reductions across all socio-economic levels, protect historic properties, protect strategic assets, and support oil and gas operations. As previously mentioned the trapped sediments in the spillways are a low-cost and historically-significant building material. The trapped sediments can be sold to offset some of the operations and maintenance costs. These highquality sediments can be used to make the southern Louisiana coastline more sustainable.

\section{Gradual siltation of impoundments}

These impoundments will gradually silt up over time thus mimicking the natural land building process and counteracting the effects of land subsidence. As previously mentioned, it would be possible to segment these large impoundments such that as one area becomes too silted, the freshwater release gates can be opened and the area can be managed to promote bayou and marshlands. The adjacent area can then be used as an impoundment for the next cycle. This sustainable land building program will enhance the local culture, distribute flood risk reductions among all surrounding communities, protect historic properties, protect strategic assets, and support oil and gas land-based operations. The siltation occurs automatically and this has no specific operation and maintenance costs.

\section{Seaward embankments function as seawalls}

The seaward boundaries of these impoundments provide the function of a seawall protecting vulnerable communities and industries by limiting the total volume of hurricane storm-surge water that can progress inland. This seawall function, with its associated decrease in flooding hazard, directly protects the cultural heritage, distributes flood risk reductions among all socio-economic groups, protects historic properties, protects strategic assets, and supports oil and gas development. These embankment seawalls will mimic the natural ridges that have been deteriorating. The erosion that will occur on these embankments can be repaired with low-cost harvested sediments from the sediment traps and bioengineered slope protection.

\section{CONCLUSIONS}

The proposed impoundment of freshwater and sediments in low-lying areas between the Mississippi River and the Gulf Coast can mimic the delta building function of the presently inactive deltas in southern Louisiana. This innovative system-level river management approach can positively address each of the nine decision criteria presented by the CPRA in the 2012 Coastal Master Plan. Large impoundments of freshwater and sediments can decrease: (1) the loss of coastline; (2) the severity of coastal flooding; and (3) annual maintenance dredging costs.

\section{REFERENCES}

\footnotetext{
Alam, S. (2009) Let us try to save the vanishing Mississippi River delta. Louisiana Civil Engineer, Journal of the Louisiana Section 17(2), 6-13.

Kolb, C.R. and Van Lopik, J.R. (1958) Geology of the Mississippi River deltaic plain Southeastern Louisiana. Technical Report No. 3-483, Volume 1, US Army Engineer Waterways Experiment Station, Vicksburg, Mississippi, 120 pp.

Nordin, C.F. and Queen, B.S. (1992) Particle size distributions of bed sediments along the thalweg of the Mississippi River, Cairo, Illinois, to Head of Passes, September 1989. Potamology Program (P-1), Report 7, 93 pp.

Thorne, C., et al. (2008) Current and historical sediment loads in the Lower Mississippi River, Final Report to European Research Office of the U.S. Army, London, England, from School of Geography, University of Nottingham, 146 pp.
} 